\title{
Prototypicality of emotions: A reaction time study
}

\author{
BEVERLEY FEHR, JAMES A. RUSSELL, and LAWRENCE M. WARD \\ University of British Columbia, Vancouver, British Columbia V6T IW5, Canada
}

\begin{abstract}
A reaction time study showed that the concept of emotion is more like a prototypically organized concept than a classically defined one. Emotion terms rated as better examples of "emotion" (such as anger) were verified as emotions faster than were terms rated as poorer examples (such as awe).
\end{abstract}

Although it has played an important role in psychology, the concept of emotion has so far eluded definition. Definitions have, of course, been offered, but little agreement has been reached (see Plutchik's 1980, extensive review). Such a singular lack of success raises the question whether a definition of the concept of emotion is even possible, that is, a definition in the classical sense whereby concepts are defined by a set of singly necessary and jointly sufficient attributes.

Various investigators (e.g., Mervis \& Rosch, 1981; Smith \& Medin, 1981) have recently begun to explore the notion that individuals may not understand all concepts in terms of classical definitions. Rosch and her associates proposed an alternative, the prototype view, in which concepts are organized around prototypes, which are the clearest cases or best examples of the concept. Here, we address the question whether emotion might not be better understood from the prototype point of view than it has been from the classical one.

One property of a prototypically organized concept is that some of its instances are better examples of that concept than are others. Some members are central and others peripheral, whereas in a classically defined concept, since all instances possess all defining attributes, all members are presumably equal in centrality. Rosch (1973) found, for example, that subjects could reliably rate how good an example of the concept "bird" were robins, eagles, chickens, and penguins. These typicality ratings, in turn, predicted how long subjects took to verify sentences of the form "An X is a bird." Subjects took longer when peripheral than when central members were substituted for $\mathbf{X}$.

In the present study, subjects were asked to verify sentences of the form " $\mathrm{X}$ is an emotion" in order to test the hypothesis that it would take longer to verify the sentence for less typical emotions than for more typical ones.

\section{METHOD}

The subjects were 20 students of the University of British Columbia who volunteered to participate in research. Subjects were required to respond "true"or "false" to 80 statements of the form " $\mathrm{X}$ is $\mathrm{a} / \mathrm{n} \mathrm{Y}$." The pool of statements consisted of (1) 10 true central emotion statements such as "Anger is an emotion," (2) 10 true peripheral emotion statements such as "Awe is an emotion," (3) 10 false central emotion statements such as "Joy is a sport," (4) 10 false peripheral emotion statements such as "Respect is a fruit," (5) 10 true central vehicle statements such as "Truck is a vehicle," (6) 10 true peripheral vehicle statements such as "Wagon is a vehicle," (7) 10 false central vehicle statements such as "Car is a tool," and (8) 10 false peripheral vehicle statements such as "Skate is a bird."

The emotion statements were composed from 20 emotion terms, 10 of which had been rated typical and 10 less typical examples of emotions (Fehr \& Russell, Note 1). The 10 typical emotions were love, anger, hate, sadness, happiness, fear, depression, joy, excitement, and guilt (for which average typicality ratings ranged from 4.5 to 5.5 on a scale from $1=$ extremely poor example to $6=$ extremely good example). The 10 less typical emotions were embarrassment, envy, anxiety, worry, disgust, awe, pride, calm, boredom, and respect (for which average typicality ratings ranged from 2.5 to 4.4 on the same scale). The vehicle statements were taken from Rosch (1973) and were included in order to replicate her findings and to provide filler items for the task.

A computer program was written to present the 80 statements once each in a different random order for each subject. The following instructions were presented on the screen of a TRS-80 Radio Shack computer: "This is a study of the "belongingness' of items in categories. You will be presented with a series of statements of the form ' $\mathrm{X}$ is $\mathrm{a} / \mathrm{n} \mathrm{Y}$ '. Your task is to respond TRUE or FALSE to each statement as fast as you can. So, for example, if the sentence 'Apple is $a / n$ fruit' appeared on the screen, you would press the ' 1 ' key for TRUE. If the statement 'Apple is $a / n$ clothing' appeared, you would press the ' 2 ' key for FALSE. Try to respond as quickly and as accurately as you can."

Subjects were ushered into the laboratory, where the instructions for the task were displayed on the computer terminal. They were told to read the instructions and press the "Enter" key when they understood the instructions and were ready to begin. The word READY appeared before each sentence to alert the subject that a sentence would be displayed. Subjects took approximately $15-20 \mathrm{~min}$ to complete the task.

\section{RESULTS}

Reaction times were analyzed only for correct responses. A response was considered correct if the subject responded "True" to a true central or peripheral statement and "False" to a false central or peripheral statement. Number of, and mean reaction times for, correct responses appear in Table 1 for each type of sen- 
Table 1

Mean Reaction Time (in Milliseconds) in the Category Verification Task

\begin{tabular}{lcc}
\hline & $\begin{array}{c}\text { Mean Reaction } \\
\text { Time }\end{array}$ & $\begin{array}{c}\text { Mean N } \\
\text { Correct }\end{array}$ \\
\hline \multicolumn{1}{c}{$\begin{array}{c}\text { Emotion Statements } \\
\text { True Central }\end{array}$} & 1193 & \\
True Peripheral & 1361 & 8.3 \\
False Central & 1541 & 7.0 \\
False Peripheral & 1626 & 7.6 \\
\multicolumn{1}{l}{ True Central } & Vehicle Statements & 7.7 \\
True Peripheral & 1257 & \\
False Central & 1425 & 9.3 \\
False Peripheral & 1306 & 6.3 \\
\end{tabular}

Note-Maximum possible number correct is 10.00 .

tence. Dependent-sample $t$ tests revealed a significant difference between reaction times to central and peripheral true emotion statements $[\mathrm{t}(29)=2.69, \mathrm{p}<.01$, onetailed test], such that sentences containing central members were verified more quickly. The difference in number correct between central and peripheral true emotion statements was also significant $[\mathrm{t}(29)=2.34$, $\mathrm{p}<.05]$. Subjects responded "true" more often to true central statements than they did to true peripheral statements. The difference in reaction time between central and peripheral false emotion statements was not significant $[\mathrm{t}(29)=1.31, \mathrm{p}=.10]$.

For the vehicle statements, a significant difference was found between central and peripheral true vehicle statements $[\mathrm{t}(29)=1.86, \mathrm{p}<.05$, one-tailed test $]$. The difference between central and peripheral false statements was not significant $[\mathrm{t}(29)=1.45, \mathrm{p}<.10]$. Number correct differed between central and peripheral true vehicle statements $[\mathrm{t}(29)=6.67, \mathrm{p}<.0001]$.

\section{DISCUSSION}

The results were as hypothesized. Subjects took longer to verify the truth of a statement like "Awe is an emotion" than to verify a statement like "Anger is an emotion." Central members of the concept "emotion" were identified as such more quickly, whereas more deliberation occurred before peripheral membership was verified. This finding was corroborated in the number correct results: Subjects made more errors in the case of peripheral category exemplars. This result suggests that subjects were unsure of, and therefore hesitant to verify, the category membership of the peripheral cases; membership of the central members was less contested.

The same pattern of results emerged for the vehicle statements, thereby replicating Rosch's (1973) findings. Subjects were less likely to, and took longer to, verify the truth of a statement like "Wagon is a vehicle" than to verify a sentence like "Truck is a vehicle."

These results suggest that statements about what is and what is not an emotion cannot always be seen, as the classical view would have it, as absolutely true or false. Rather, their truth seems to be a matter of degree.

\section{REFERENCE NOTE}

1. Fehr, B., \& Russell, J. A. A prototype view of the concept of emotion. Unpublished manuscript, University of British Columbia, 1982.

\section{REFERENCES}

Mervis, G., \& Rosch, E. Categorization of natural objects. Annual Review of Psychology, 1981, 32, 89-115.

Plutchik, R. Emotion: A psychoevolutionary synthesis. New York: Harper \& Row, 1980.

Rosch, E. On the internal structure of perceptual and semantic categories. In T. E. Moore (Ed.), Cognitive development and the acquisition of language. New York: Academic Press, 1973.

Smith, E. E., \& Medin, D. L. Categories and concepts. Cambridge, Mass: Harvard University Press, 1981.

(Received for publication September 21, 1982.) 